\section{Comparison of the C-Mac video laryngoscope with the McGrath Series 5 video laryngoscope concerning an extremely difficult airway}

\section{Tomasz Gaszyński}

Department of Anaesthesiology and Intensive Care, Medical University of Łódz, Poland

Section for Instrumental Restoration of Airway Patency, Polish Society of Anaesthesiology and Intensive Care

A 51-year-old patient was admitted to the University Hospital for middle ear surgery. Six years earlier the patient had undergone a thyroidectomy due to cancer, followed by radiation therapy to the neck area. Potential difficult intubation associated with post-radiation lesions was tested and revealed a mouth opening of approximately $2 \mathrm{~cm}$, reduced neck mobility and highly positioned larynx resisting movements.

As airway manipulations under local anaesthesia were poorly tolerated by the patient, inhalation anaesthesia with sevoflurane was provided with spontaneous breathing preserved [1]. Due to the small mouth opening, the attending anaesthetist attempted to use the TotalTack video laryngoscope (Medcomflow, Barcelona, Spain). Unfortunately, the attempt failed because of very restricted mouth opening (Fig. 1). It was decided to use the McGrath Series 5 instead (Aircraft Medical, UK). Although the blade was successfully placed in the mouth, only the epiglottis was visualized (Fig. 2). Due to postradiation lesions, the larynx was immobilized and the pressure exerted on the organ did not improve the vision visiualisation of entrance to larynx. A decision was then made to use the C-Mac D-blade video laryngoscope (Storz, Germany) and the laryngeal aperture was visualized (Fig. 3). Unfortunately, the laryngeal lumen was found to be considerably narrowed by neoplastic proliferation. The Frova introducer (Cook, Great Britain) was inserted into the larynx, ensuring ventilation through its lumen, and jet ventilation was applied using a Ventrain ventilation device (Dolphys Medical, Eindhoven, Holland). At the same time tracheotomy was started, which, however, was extremely difficult due to technical problems - postradiation lesions. Indeed, an experienced laryngologist had serious problems identifying the trachea. The anaesthesiologist performed a tracheal puncture, inserted the introducer and a (surgical) tracheotomy was performed. After restoration of airway patency and consultations with surgeons, it was decided to postpone the procedure and the patient was admitted to the intensive care unit for observation and diagnosis of neoplastic proliferation of the larynx. A chest x-ray revealed pneumothorax on the

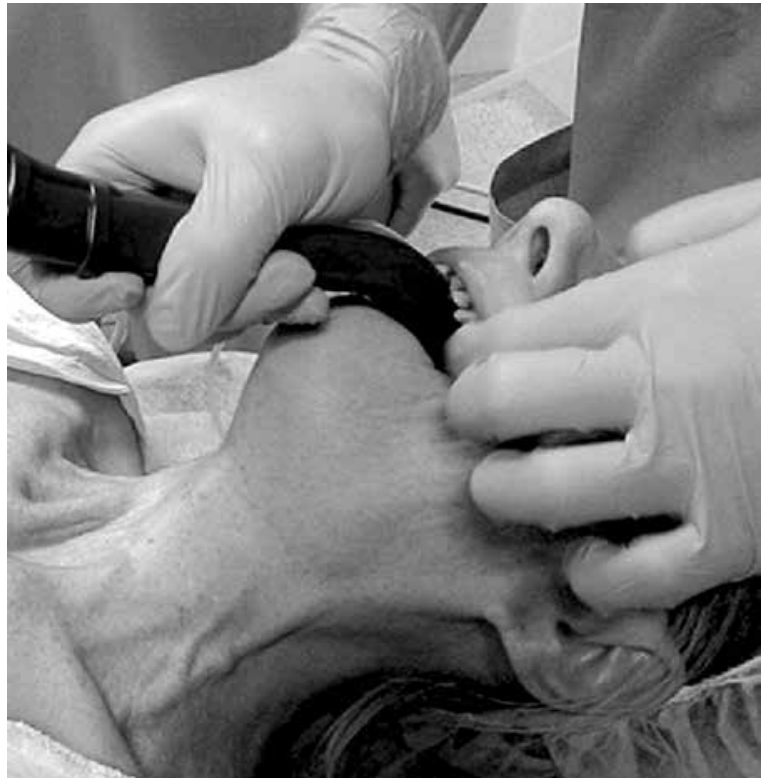

Figure 1. Attempt to introduce TotalTrack in the patient's mouth

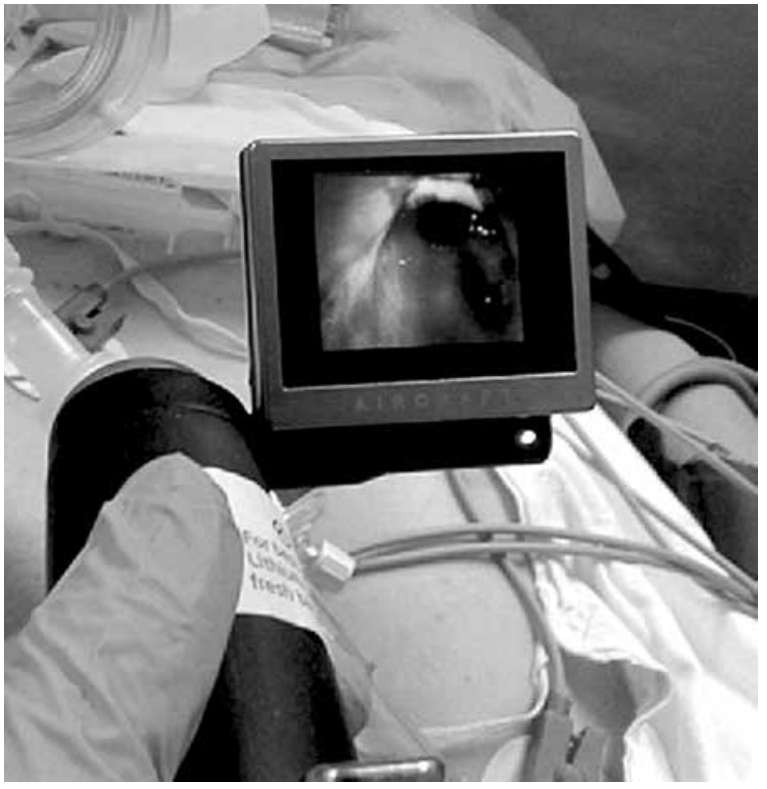

Figure 2. Image obtained using the McGrath Series 5 video laryngoscope

left side, which was secured. Moreover, an ultrasound of the larynx was performed which revealed a larynx with proliferating cells (Fig. 4).

Patients with potentially difficult airways should have them secured using awake intubation or pre-operative tracheotomy under local anaesthesia. However, if a patient does not tolerate airway manipulations under local anaes- 


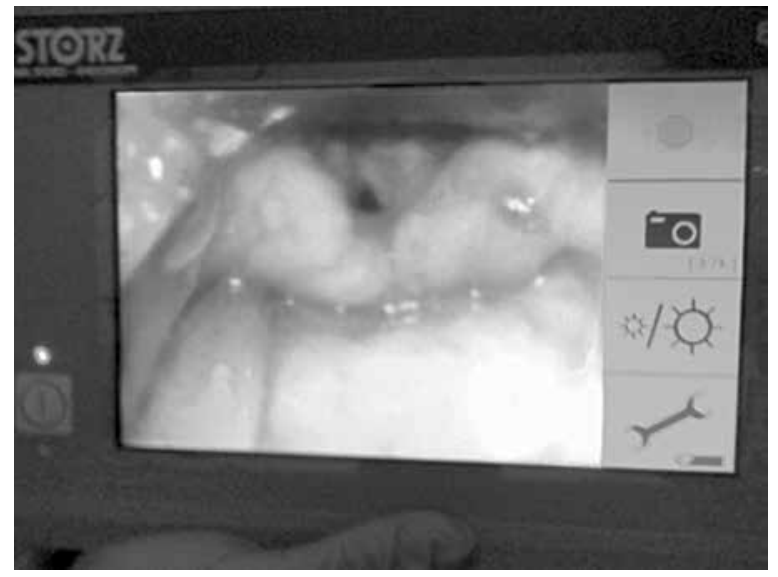

Figure 3. Image of the larynx in the C-Mac video laryngoscope with D-blade

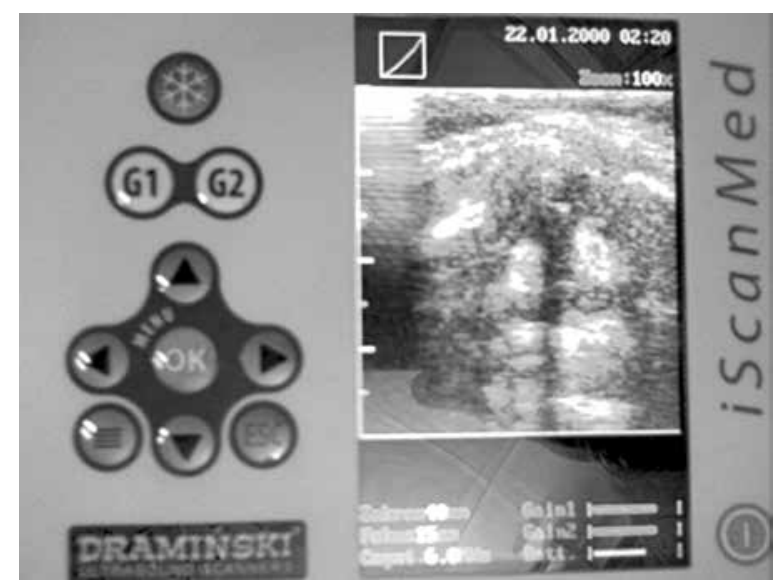

Figure 4. Larynx ultrasonography

thesia, general anaesthesia with spontaneous breathing preserved should be performed [1].

The Total Track video laryngoscope, a new device on the market, has many interesting characteristics - it enables ventilation during attempts at visualizing the larynx and intubation. Unfortunately, the device, although dedicated also for patients with small mouth openings, was found to be ineffective as an attempt to place it in the patient's mouth failed. Another video laryngoscope - the McGrath Series 5 - recommended for "difficult intubations" did not allow satisfactory visualisation of the laryngeal aperture either - a CL 3/4 image was obtained. Full visualization was achieved with the C-Mac Storz D-blade - CL 1 scale. The D-blade is designed for extremely difficult intubations; it is bent at a larger angle than the blades of the Macintosh type (Fig. 5). There are no literature reports comparing the technical characteristics of the various video laryngoscopes or their use in patients with extremely difficult airways. Ac-

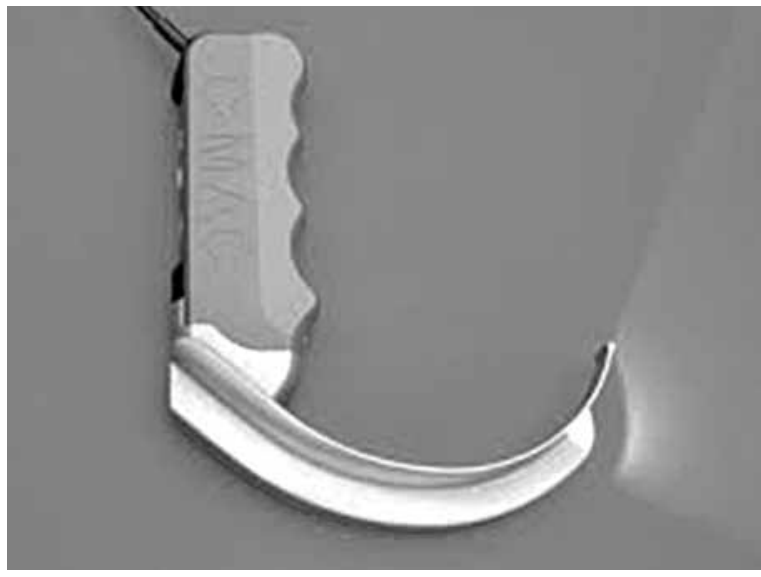

Figure 5. C-Mac D-blade (source: advertising materials)

cording to the only study available carried out on patients with potentially difficult airways, the results obtained with the McGrath and C-Mac video laryngoscopes were similar: a higher percentage and shorter time of successful intubations were reported for the C-Mac [2].

In the case discussed here, ventilation was performed using a Ventrain device through the Frova introducer. This option is described by the producer and may be used as an alternative to intubation with an endotracheal tube [3].

Surgical tracheotomy can be difficult, especially in patients with altered anatomy, e.g. after radiation therapy, as in our case. Airway ultrasound, which is a simple and noninvasive procedure, enables visualisation of the larynx and trachea and can help perform tracheotomy in very "difficult" patients. Ultrasound of the larynx and trachea is recommendable in all patients with potential difficult airway [4].

In conclusion, video laryngoscopes differ in technical characteristics, including the intensity of light and field of vision. The case reported by us has demonstrated the superiority of the C-Mac with a D-blade over the McGrath Series 5 ; the former provides better visualisation of the laryngeal aperture, as compared to the latter.

\section{ACKNOWLEDGEMENTS}

The author has received remuneration from Skamex distributor McGrath video laryngoscopes and from Medim - distributor C-Mac video laryngoscopes for lectures on airway management.

\section{References:}

1. Andres J, Gaszyński W, Jałowiecki P, Kübler A, Mayzner-Zawadzka E, Nestorowicz A: Wytyczne stosowania wziewnej indukcji i podtrzymywania znieczulenia. Anestezjol Intens Ter 2007; 39: 57-59.

2. $\mathrm{Ng}$ l, Hill AL, Williams $D L$, Lee $K$, Segal R: Randomized controlled trial comparing the McGrath videolaryngoscope with the C-MAC videolaryngoscope in intubating adult patients with potential difficult airways. Br J Anaesth 2012; 109: 439-443. doi: 10.1093/bja/aes145. 
3. KalkoffM, Shetty S:Ventilation through a small bore intubating catheter using Ventrain in an elective procedure. http://bja.oxfordjournals.org/ forum/topic/brjana el;9580; 18.12.2012.

4. Kristensen MS, Teoh WH, Graumann O, Laursen CB: Ultrasonography for clinical decision-making and intervention in airway management: from the mouth to the lungs and pleurae. Insights Imaging 2014; 5: 253-279. doi: 10.1007/s13244-014-0309-5.

\section{Corresponding author:}

Prof. Tomasz Gaszyński MD, PhD

Department of Emergency Medicine

and Disaster Medicine Barlicki

University Hospital

ul. Kopcińskiego 22, 90-153 Łódź, Poland

e-mail: tomasz.gaszynski@umed.lodz.pl

Anaesthesiology Intensive Therapy 2016 , vol. 48 , no $1,57-58$ ISSN 0209-1712

\section{Commentary to "Remifentanil for labour pain relief"}

\author{
Radosław Chutkowski, Bartłomiej Wódarski, \\ Małgorzata Malec-Milewska \\ Department of Anaesthesiology and Intensive Care, Medical Centre \\ for Postgraduate Education, W. Orlowski University Hospital \\ in Warsaw
}

\section{To the Editor,}

It was with great interest that we read the review paper entitled "Remifentanil for labour pain relief" by Dr Joanna Solek-Pastuszka et al., published in issue no. 1/2015 of Anaesthesiology Intensive Therapy [1].

The problem of labour pain relief remains an important issue that requires our constant attention and improvement. The disadvantages of pethidine listed in the article are undisputable. However, we should ask ourselves whether, despite its popularity, or maybe precisely because of it, we should talk more decisively about the necessity to stop using it altogether in the delivery room. Next year, two decades will have passed since the publication of Olofsson's article in the British Journal of Obstetrics and Gynaecology, in which he made it very clear that the use of pethidine during labour is unethical and medically erroneous [2]. In 1997, in The Lancet, Raynolds and Crowhurts equally strongly opposed the use of opioids (pethidine and morphine) for labour pain relief, finding it unjustified [3].

In light of their findings, remifentanil seemed a good alternative, which had been demonstrated by numerous studies from the beginning of the 21st century to which the authors refer [1]. However, it should also be pointed out that during the second decade of the 21st century, opinions as to the administration of this drug are no longer so clear $[4,9,10]$.

Firstly, the use of remifentanil during labour can lead to sedation and respiratory depression. The literature has reported numerous cases (concerning as much as $27 \%$ of study participants) in which $\mathrm{SpO}_{2}$ in mothers dropped to 91-92\% and the use of oxygen was necessary [4]. In recent years even more alarming reports have been published. These concern cases of severe respiratory depression, or even respiratory arrest, in parturients administered intravenous remifentanil $[6,7]$.

Secondly, the question should be asked whether patients treated with this method have the same comfort of labour as when neuraxial anaesthesia is employed. This comfort does not only refer to pain but also the possibility of "walking analgesia", of moving and assuming different labour positions, which is restricted by the necessity of continuous $\mathrm{HR}$, $\mathrm{RR}$ and $\mathrm{SaO}_{2}$ monitoring, as well as an additional intravenous line (a pump with remifentanil), often in addition to an already working pump with oxytocin. Moreover, it is of importance that the parturient is affected by opioid sedative action, which may have significant impact on the psychological labour and birth experience.

Thirdly, the hyperalgesic potential of remifentanil, as demonstrated in animal studies, should be taken into account [8].

Although the above findings do not erase the advantages of remifentanil, they do tell us to approach this method with more caution. Experts have pointed out "significant side effects" and recommend very scrupulous and continuous monitoring of vital signs, as stated by Van Der Velde in his article in Current Opinion in Anesthesiology of March 2015 entitled "Patient-controlled intravenous analgesia remifentanil for labor analgesia: time to stop, think and reconsider." $[9,10]$.

Another issue raised by the authors concerns contraindications for central blocks in parturients which are the gold standard of anaesthesia in spontaneous delivery [1].

At our hospital, epidural analgesia is performed in $85 \%$ of spontaneous deliveries. Therefore, based on many years of experience, we believe that obesity should not be treated as a "technical contraindication". We also anaesthetise (epidural, CSE, CSA, spinal) patients undergoing spontaneous delivery, whose BMl exceeds $45 \mathrm{~kg} \mathrm{~m}^{-2}$, and we even had a recent case of a BMI of $65 \mathrm{~kg} \mathrm{~m}^{-2}$. It should only be remembered that in such parturients epidural anaesthesia ought to be performed as skilfully and safely as in other anaesthetic procedures. Therefore, in patients with a BMI exceeding $40 \mathrm{~kg} \mathrm{~m}^{-2}$ ultrasonographic identification is routinely used during central blocks (epidural, CSE, CSA). Moreover, it is 
worth remembering that the oxygen reserve in parturients is physiologically absent (low FRC), which in cases of respiratory depression necessitates immediate intervention. Maintenance of patent airways in an obese patient additionally complicates the situation, creating a real threat to the life of both mother and her unborn child. Therefore, we agree with experts that parenteral opioids should not be used in spontaneous delivery anaesthesia as a routine [4]. In cases of potential contraindications to central blocks, inhalation agents should be considered [11].

We agree with the authors of the discussed paper as to the necessity to improve the availability and conditions of labour analgesia in Poland and that each medical centre should develop its own standards. However, having in mind the safety and comfort of parturients, we recommend performing epidural analgesia (or other central neuroaxial blocks) as widely as possible, as it remains the gold standard of management.

\section{ACKNOWLEDGEMENTS}

1. The authors declare no financial disclosure.

2. The authors declare no conflict of interest.

\section{References:}

1. Solek-Pastuszka J, Zagrodnik-Ulan E, Bohatyrewicz $R$ et al.: Remifantanil for labour pain relief. Anaesthesiol Intensive Ther 2015; 47: 82-86. doi: 10.5603/AIT.2015.0008.

2. Olofsson C, Ekblom A, Ekman-Ordeberg Get al.: Lack of analgesic effect of systemically administered morphine or pethidine on labour pain. Br J Obstet Gynaecol 1996; 103: 968-972.
3. Reynolds F, Crowhurst JA: Opioids in labour - no analgesic effect. Lancet 1997; 349: 4-5.

4. Tveit TO, Halvorsen A, Seiler S et al.: Efficacy and side effects of intravenous remifentanil patient-controlled analgesia used in a stepwise approach for labour: an observational study. Int J Obstet Anesth 2013; 22: 19-25. doi: 10.1016/j.ijoa.2012.09.003.

5. Freeman $L M$, Bloemenkamp KW, Franssen MTet al.: Patient controlled analgesia with remifentanil versus epidural analgesia in labour: randomised multicentre equivalence trial. BMJ 2015; 23; 350. doi: 10.1136/bmj.h846.

6. Bonner JC, McClymont W: Respiratory arrest in an obstetric patient using remifentanil patient-controlled analgesia. Anaesthesia 2012; 67: 538-540. doi: 10.1111/j.1365-2044. 2011.06997.x.

7. Pruefer $C$, Bewlay A: Respiratory arrest with remifentanil patient-controlled analgesia - another case. Anaesthesia 2012; 67: 1044-1045. doi: 10.1111/j.1365-2044.2012.07273.x.

8. Kim SH, Stoicea N, Soghomonyan Set al.: Intraoperative use of remifentanil and opioid induced hyperalgesia/acute opioid tolerance: systematic review. Front Pharmacol 2014; 8: 108.

9. Kranke P, Girard T, Lavand'homme Pet al.: Must we press on until a young mother dies? Remifentanil patient controlled analgesia in labour may not be suited as a "poor man's epidural". BMC Pregnancy Childbirth 2013; 13: 139. doi: 10.1186/14712393-13-139.

10. Van de Velde M: Patient-controlled intravenous analgesia remifentanil for labor analgesia: time to stop, think and reconsider. Curr Opin Anesthesiology 2015; 28: 237-239. doi: 10.1097/ ACO.0000000000000191.

11. Rosen MA: Nitrous oxide for relief of labor pain: a systematic review. Am J Obstet Gynecol 2002; 186: 110-126.

\section{Corresponding author:}

Bartłomiej Wódarski

Department of Anaesthesiology and Intensive Care

Medical Centre for Postgraduate Education

W. Orlowski University Hospital in Warsaw

ul. Czerniakowska 231,00-416 Warszawa

e-mail:barwoda@gmail.com

\section{In reply to the commentary to Commentary to "Remifentanil for labour pain relief"}

\author{
Joanna Solek-Pastuszka ${ }^{1}$, Edyta Zagrodnik-Ulan², \\ Romuald Bohatyrewicz ${ }^{1}$, Zbigniew Celewicz ${ }^{3}$ \\ ${ }^{1}$ Chair and Department of Anaesthesiology and Intensive Therapy, \\ Pomeranian Medical University in Szczecin, Poland \\ ${ }^{2}$ Department of Adult and Paediatric Anaesthesiology and Intensive \\ Therapy, Pomeranian Medical University in Szczecin, Poland \\ ${ }^{3}$ Department of Pregnancy and Labour, Pomeranian Medical \\ University, Teaching Hospital no. 1, Police, Poland
}

In response to the letter of Radosław Chutkowski et al., I would like to thank them for their opinion in the discussion. The remarks and doubts of Dr Chutkowski regard a number of issues I would like to address.
Although I do agree that pethidine should be consigned to history, this is not yet the case, a fact which is evidenced by national and international reports of its common use, despite its negative reputation in numerous medical facilities [1]. I also agree that "remifentanil seemed a good alternative..." in comparison to other opioids used parenterally in labour analgesia; even more, I believe it is still such an alternative, a view that is also shared by the authors of the publications quoted by Dr Chutkowski.

Based on the publications of Tveit and Freeman, Chutkowski claims that using remifentanil may lead to sedation and respiratory depression. However, detailed analysis of Trevit's report [2] gives us important information that has escaped Dr Chutkowski's notice. Trevit discontinued the PCA infusion and used $\mathrm{O}_{2}$ supplementation when the concentration of $\mathrm{SaO}_{2}$ dropped below $92 \%$ or when the respiratory rate was less than $9 \mathrm{~min}^{-1}$. Subsequently, after the normalization of parameters, 
he reassumed PCA with a smaller bolus dose (a step dose). In the conclusions of the abstract, Tveit also wrote that remifentanil administered intravenously in PCA ensures proper labour analgesia and the high satisfaction of a parturient during the first and the second period of labour. Although, sedation and respiratory depression may occur, there is no evidence of significant side effects it could have on a newborn. It goes without saying that careful monitoring of a parturient is mandatory.

Special attention should also be paid to the other report quoted, namely the paper by Freeman et al. [3]. This presents the results of a multicenter study carried out in Holland on a group of parturients with 447 of them administered remifentanil in PCA and 347 undergoing central epidural analgesia. It has escaped doctor Chutkowski's notice that desaturation, although concerning a smaller yet relevant percentage, i.e. $5 \%$, also appeared in the central epidural analgesia group. This means that regardless of the method applied, oxygen supplementation may be required. Furthermore, some other complications developed in the central epidural analgesia group, which were not found in the group with remifentanil alone; these included hypotension and post-puncture headaches. It is worth stressing that pulse oximeter readings suggesting desaturation may not be connected with the type of analgesia used and may be caused by the clenching of hands. While placing the sensor in another location could help to settle this dilemma, as results from the publication by Stocki show, parturients do not accept such solutions [4].

Dr Chutkowski writes as follows: "In recent years even more alarming reports have been published. They concern cases of severe respiratory depression, or even respiratory arrest, in parturients administered intravenous remifentanil", basing this on the publications of Bonner and Pruefer $[5,6]$. Meanwhile, the quoted authors themselves admit that these complications were caused by basic human error. Bonner states that it is not certain whether remifentanil is indeed the only causative factor. In the case discussed, a 17-yearold patient of unknown body weight during a pregnancy ending with stillbirth, received remifentanil in a high dose of $40 \mathrm{mcg} / \mathrm{bolus}$ with a 2-minute refractory period. In total, during 5 hours she was given $4 \mathrm{mg}$, which is a high dose. Moreover, other factors appeared, such as the patient's exhaustion, vomiting, dehydration and reduced nursing supervision since there was no need to monitor the fetal vital signs. When the family reported that the patient had lost consciousness, oxygen ventilation was applied immediately and consciousness and independent ventilation were restored after approximately 40 seconds.

The other author - Pruefer - in his report did not exclude the possible overlapping of effects of fentanyl, administered earlier epidurally, with the cumulative action of several bolus doses of remifentanil. Such a mistake might have appeared due to the attachment of a PCA infusion to the cannula with other infusions and its temporal obstruction. When apnoea was noticed, the patient was turned to the left lateral decubitus position and an oxygen ventilator was used. Subsequently, apnoea subsided within 30-60 seconds. After this incident, PCA remifentanil was decided upon through a separate vascular access dedicated only to this infusion. Both authors unanimously stress the necessity of monitoring the parturient by a mid-wife in a 1:1 ratio, and do not negate the further use of remifentanil on their wards.

Moreover, Dr Chutkowski claims that analgesia with remifentanil causes discomfort to patients. In my opinion, some publications cited by the doctor contradict this. Indeed, Tveit states that $88 \%$ of his patrurients would chose the same analgesia again, i.e. the administration of remifentanil. In a paper by Stocki, published in 2014, concerning a randomized study comparing remifentanil and central epidural analgesia in parturients, we read that remifentanil PCA, despite worse analgesic effects, provides patients with better comfort than central epidural analgesia. Interestingly, in this study, patients randomized to the central epidural analgesia group were not pleased with the choice, which indicates the popularity of analgesia with remifentanil, despite its undeniably poorer efficacy. Although, I do agree with my colleague that using remifentanil excludes "walking analgesia", parturients with central epidural analgesia and an additional oxytocin infusion which the doctor mentions, will also have difficulty walking.

Citing a paper by Kim [7], Chutkowski states: "Thirdly, what should also be taken into account are the reports concerning the high hyperanalgesic potential of remifentanil, demonstrated in animal tests"; most likely, he was thinking of hyperalgesia. I would like to point out that, despite what the doctor claims, this study was not limited to animals and included humans as well. While Hyperalgesia caused by remifentanil discussed in the paper is known, in this particular case it concerned high doses used during a perioperative period and over a longer period of time. The phenomenon was not observed with doses used in labour analgesia.

Although he title of Van der Velde's paper cited "Patientcontrolled intravenous analgesia remifentanil for labour analgesia: time to stop, think and reconsider" [8] sounds serious, the safety issues it concerns are also essential elements of our specialization. Kranke, the other of the quoted "opponents" of remifentanil poses this question in the title of his paper: "Must we press on until a young mother dies?" [9]. After thorough investigation of the abovementioned reports, it is clear to see that their authors warn against the introduction of the method in question as a first-choice method, justified inter alia by a possible reduction in analgesia costs. They both agree that in such situations thinking about cost-effectiveness may have catastrophic results and that under no circumstances can we give up direct nursing supervision over the patient in a 1:1 ratio. However, it 
should also be emphasised that they both claim that PCA remifentanil can be a real alternative to other methods of labour analgesia. Indeed, I have presented the same view on safety in my own paper.

In analysing the possibilities of labour analgesia in Poland, the author discusses the experiences of his own team. In technically difficult situations involving central epidural analgesia, he suggests ultrasonographic identification of anatomic structures. Although this is a very good solution, unfortunately ultrasonography is not widely available and not all medical facilities have an anaesthetic team with a lot of experience in this method. Therefore, focusing on the availability of labour analgesia in Poland, all obstetric departments and the real chances of the safe performance of procedures should be considered. Thus, the methods mastered only by referral centres should not be recommended for widespread use.

The other central blocks mentioned by the author (CSA, CSE) sometimes cannot be used due to medical contraindications or the lack of the patient's consent. Moreover, it should be stressed that CSA is not a commonly used method. The data concerning its induction is still too scarce for this method to be recommended as the standard one. Therefore, I believe that epidural analgesia, CSE and CSA are not methods that can be used interchangeably.

While discussing their unquestionable achievements, the authors neglected the possible adverse events that can develop during central blockades. Although rare, they cannot be disregarded. Post-puncture headaches are most commonly observed. If they develop, the patient is immobilized, which considerably limits her possibility of breastfeeding on request — and this, in turn, may disrupt the emotional bond between mother and child, a problem that the authors also mention.

Moreover, the authors quote Kranke, who thinks that although central epidural analgesia is the gold standard in labour analgesia, also notices the severe adverse effects that may accompany this method, such as improper catheter placement (intravascularly, subarachnoidally). As the author mentions, instant intervention to ensure ventilation is needed in such cases, and, similarly, in cases of hypoventilation caused by remifentanil. The major difference is that in the case of remifentanil, hypoventilation usually subsides after several dozen seconds, whereas complications of regional analgesia - respiratory depression and circulatory disorders - generally last slightly longer [10]. Such situations are not even mentioned by the author.

Furthermore, I do not agree with the opinion that the use of inhalation anaesthetics as an alternative to central epidural analgesia is justified, except for situations when no other option is available. However, I do agree with the authors cited by Dr Chutkowski concerning the poor analgesic effects of these agents and their unknown influence on the child's developing brain [9].
To conclude, I agree with part of conclusions presented by $\operatorname{Dr}$ Chukowski namely, that epidural analgesia remains the gold standard in labour analgesia. However, I believe that remifentanil PCA should be accepted as an alternative standard much as it is used worldwide, which is unanimously confirmed by all the authors cited by my colleague.

Summing up, I would like to finish this discussion with the following important conclusions:

1. Remifentanil PCA can be a valuable alternative to central epidural analgesia when the latter is difficult to apply or infeasible

2. The use of remifentanil PCA requires direct continuous nursing supervision over the parturient in a 1:1 ratio and the possible periodic use of oxygen, if necessary

3. Rules for the use of remifentanil PCA, in the form of recommendations, should be developed by the appropriate Polish scientific societies.

\section{ACKNOWLEDGEMENTS}

1. The authors declare no financial disclosure.

2. The authors declare no conflict of interest.

\section{References:}

1. Kranke P, Girard T, Lavand'homme Pet al:: Must we press on until a young mother dies? Remifentanil patient controlled analgesia in labour may not be suited as a"poor man's epidural". BMC Pregnancy Childbirth 2013; 13: 139. doi: 10.1186/1471-2393-13-139.

2. Tveit TO, Halvorsen A, Seiler S et al.: Efficacy and side effects of intravenous remifentanil patient-controlled analgesia used in a stepwise approach for labour: an observational study. Int J Obstet Anesth 2013;22: 19-25. doi: 10.1016/j.ijoa.2012.09.003.

3. Freeman LM, Bloemenkamp KW, Franssen MTet al.: Patient controlled analgesia with remifentanil versus epidural analgesia in labour: randomised multicentre equivalence trial. BMJ 2015; 23; 350. doi: $10.1136 / \mathrm{bmj}$.h846.

4. Stocki D, Matot I, Einav S et al.: A randomized controlled trial of efficacy and respiratory effects of patient-controlled intravenous remifentanil analgesia and patient-controlled epidural analgesia in laboring women. Anesth Analg 2014; 118: 589-597. doi: 10.1213/ANE.0b013e3182a7cd1b.

5. Bonner JC, MCClymont W: Respiratory arrest in an obstetric patient using remifentanil patient-controlled analgesia. Anaesthesia 2012; 67: 538-540. doi: 10.1111/j.1365-2044.2011.06997.x.

6. Pruefer C, Bewlay A: Respiratory arrest with remifentanil patient-controlled analgesia - another case. Anaesthesia 2012; 67: 1044-1045. doi: 10.1111/j.1365-2044.2012.07273.x.

7. Kim SH, Stoicea N, Soghomonyan Set al.: Intraoperative use of remifentanil and opioid induced hyperalgesia/acute opioid tolerance: systematic review. Front Pharmacol 2014; 8: 108.

8. Van de Velde M: Patient-controlled intravenous analgesia remifentanil for labor analgesia: time to stop, think and reconsider. Curr Opin Anesthesiology 2015; 28: 237-239. doi: 10.1097/ /ACO.0000000000000191.

9. Wills J: Rapid onset of massive subdural anesthesia. Reg Anesth Pain Med 2005; 30: 299-302.

\section{Corresponding author:}

Joanna Sołek-Pastuszka, MD

Chair and Department

of Anaesthesiology and Intensive Therapy,

Pomeranian Medical University in Szczecin

ul. Unii Lubelskiej 1

70-252 Szczecin, Poland

e-mail:pastuszka@mp.pl 


\section{Cut-off point for switching from non- -invasive ventilation to intubation in severe ARDS. Still a spectrum of greys and whites}

\author{
Szymon Skoczyński ${ }^{1}$, Antonio M. Esquinas ${ }^{2}$ \\ ${ }^{1}$ Department of Pneumology, School of Medicine in Katowice, Poland \\ ${ }^{2}$ Intensive Care Unit, Hospital General Universitario Morales \\ Meseguer, Murcia, Spain
}

\section{Dear Editor,}

Acute respiratory failure (ARF) and aspiration pneumonia were the most frequently observed respiratory complications after acute heroin overdose requiring endotracheal intubation (ETI) and intensive care unit (ICU) admission [1]. In some selected cases of drug overdose, noninvasive ventilation (NIV) could have avoided associated complications [2].

We were fortunate to have had a chance to read an article entitled "Swift recovery of acute hypoxemic respiratory failure under non-invasive ventilation" by Pichot et al. [3]. The authors present interesting evidence regarding the possible implementation of NIV in a patient presenting acute respiratory failure (ARDS) with extremely impaired $\mathrm{PaO}_{2} / \mathrm{FiO}_{2}$ ratio. It is important to underline that the report provides new potential indication in highly selected patients which, in special circumstances, it is possible to treat ARDS with the use of NIV with high positive end expiratory pressure (PEEP) and $\mathrm{FiO}_{2}$.

However, although the dynamic changes of clinical status during treatment were explained in the article, we consider that there are some factors to take into account in order to consolidate this observation in unconscious patients, those suspected of cocaine intake and with severe impairment of arterial blood gases $\left(\mathrm{pH}=7.19, \mathrm{PaCO}_{2}\right.$ $=69 \mathrm{~mm} \mathrm{Hg}, \mathrm{PaO}_{2}=57 \mathrm{~mm} \mathrm{Hg}, \mathrm{SaO}_{2}=84 \%$ ), precise more precisely the precautions that should have been considered by the authors.

Firstly, regarding equipment and interface, the patient was treated with the Drager Evita XL Ventilator, meaning an ICU-dedicated ventilator. From a clinical point of view, in this case it would have been more clinically valuable for readers if the authors had provided data on the interface used. Such features are of particular importance as differences in dead space between oro-nasal, full-face masks and a helmet could influence optimal synchronization and leakage in a patient with severe tachypnea of 30 breathes per minute as reported $[4,5]$.

Secondly, the authors have concluded that swift recovery was influenced by high PEEP-NIV strategy. However, this strategy has well known risks, namely: a) high PEEP levels induce leaks and gastric leaks and gastric distention and risk of aspiration, b) large tidal volumes not reported by the authors (800-1200 mL), associated with high airway resistance, low respiratory system compliance, and short inspiratory time, all increasing airway pressure and air entering the stomach [6] and c) the stability of oesophageal sphincter pressure ( $~ 20-$ $-25 \mathrm{~cm} \mathrm{H_{2 }}$ O in adults) which, in turn, could vary by due to some pathways leading to gastric content aspiration possibly influenced by opiate toxicity. There is still controversy as to whether heroin-opioids may increase the risk of pulmonary aspiration by decreasing the pressure of oesophageal sphincter-intragastric pressure and hemodynamic compromise (supraventricular arrhythmia).

Thirdly, it is important to underline that the necessary high levels of $\mathrm{FiO}_{2}$ could also worsen alveolar damage and surfactant production. In this case, the $\mathrm{FiO}_{2}$ level was lower than 0.60 , this figure being the lung toxicity cut off point after 08:45 hours of treatment [7].

Fourthly, the definition of "swift time period of 10 hours is still not broadly accepted. We know from previous studies, that an inability to improve $\mathrm{PaO}_{2} / \mathrm{FiO}_{2}$ after 1 hour of NIV was a predictor of treatment failure $[8,9]$. We consider that for an appropriate extrapolation, it could be necessary to take into account other non-pulmonary factors as neurologic conditions and precise drugs.

Lastly, amiodarone infusion in a patient without severe cardiac arrhythmia with shock seems to be controversial. On the basis of the presented case history, we can assume that the patient was free of dangerous cardiac arrhythmia and the increased heart rate was probably caused by severe hypoxemia, dyspnoea, agitation and/or opiates reversed by naloxone treatment. In these circumstances, a heart rate (HR) of 171 and blood pressure (BP) of $141 / 71 \mathrm{~mm} \mathrm{Hg}$ should have been diagnosed as physiological sinus tachycardia, indicating that the improvement of oxygenation should have been effective first line treatment [10]. Moreover, amiodarone with its alveolar toxicity may cause further lung damage and a poorer prognosis [11].

In conclusion, it is necessary to emphasize that although this case report gives one important data on ARDS treatment under strict supervision in the ICU, NIV is contraindicated 
in severe ARDS patients who are unable to protect their airways' from aspiration. Finally, the swift time period is still controversial.

\section{ACKNOWLEDGEMENTS}

1. The authors declare no financial disclosure.

2. The authors declare no conflict of interest.

\section{References:}

1. GrigorakosL,SakagianniK, TsigouE,Apostolakos G, NikolopoulosG, Veldekis $D$ : Outcome of acute heroin overdose requiring intensive care unit admission. J Opioid Manag 2010; 6: 227-231.

2. Ridgway $Z A$, Pountney $A J$ : Acute respiratory distress syndrome induced by oral methadone managed with non-invasive ventilation. Emerg Med J 2007; 24: 681.

3. Pichot C, Petitjeans F, Ghignone M, Quintin L: Swift recovery of severe acute hypoxemic respiratory failure under non-invasive ventilation. Anaesthesiol Intensive Ther 2015; 47: 138-142. doi: 10.5603/AIT.a2014.0053.

4. Nava S, Navalesi P, Gregoretti C: Interfaces and humidification for noninvasive mechanical ventilation. Respir Care 2009; 54: 71-84.

5. Storre JH, Bohm P, Dreher M, Windisch W: Clinical impact of leak compensation during non-invasive ventilation. Respir Med 2009; 103: 1477-1483.

6. De Keulenaer BL, De Backer A, Schepens DR, Daelemans $R$, Wilmer A, Malbrain ML: Abdominal compartment syndrome related to noninvasive ventilation. Intensive Care Med 2003; 29: 1177-1181.

7. Aggarwal NR, Brower RG: Targeting normoxemia in Acute Respiratory Distress Syndrome may cause worse short-term outcomes because of oxygen toxicity. Ann Am Thorac Soc 2014; 11: 1449-1453. doi: 10.1513/AnnalsATS.201407-297PS.
8. Antonelli M, Conti G, Moro ML et al.: Predictors of failure of noninvasive positive pressure ventilation in patients with acute hypoxemic respiratory failure: a multi-center study. Intensive Care Med 2001; 27: 1718-1728.

9. Antonelli M, Conti G, Esquinas A et al.: A multiple-center survey on the use in clinical practice of noninvasive ventilation as a first-line intervention for acute respiratory distress syndrome. Crit Care Med 2007; 35: 18-25.

10. Blomström-Lundqvist C, Scheinman MM, Aliot EM et al.: American College of Cardiology; American Heart Association Task Force on Practice Guidelines; European Society of Cardiology Committee for Practice Guidelines. Writing Committee to Develop Guidelines for the Management of Patients with Supraventricular Arrhythmias. ACC/AHA/ESC guidelines for the_management of patients with_supraventricular arrhythmias--executive summary: a report of theAmerican_College of_Cardiology/American_Heart_AssociationTask Force_on_Practice Guidelines_and the_European_Society_of Cardiology_Committee_for_Practice Guidelines_(Writing_Committee to Develop Guidelines for the Management of Patients with Supraventricular Arrhythmias). Circulation 2003; 108: 1871-1909.

11. Dhokarh R, Li G, Schmickl CN et al.: Drug-associated acute lung injury: a population-based cohort study. Chest 2012; 142: $845-850$.

\section{Corresponding author:}

Szymon Skoczyński

Department of Pneumology, School of Medicine in Katowice,

Medical University of Silesia,

Medyków 14, 40-752 Katowice, Poland

e-mail: simon.mds@poczta.fm

\section{Cut-off point for switching from non- -invasive ventilation to intubation in severe ARDS. Fifty shades of grey?}

\author{
Luc Quintin \\ Department of Physiology, University of Lyon, Lyon, France
}

Key words: acute respiratory distress syndrome, severe ARDS, non-invasive ventilation

Sir, I would like to thank Drs Skoczyński and Esquinas for their comments. Firstly, let us turn to their secondary points: 1. The initial intention was to pre-oxygenate a severely hypoxic patient before tracheal intubation [1] with a Respironics ventilator in the emergency department (ED), not to manage the whole case under non-invasive ventilation (NIV) with an Evita $4 \mathrm{XL}$ ventilator in the Critical Care Unit (CCU). Nevertheless, the ventilatory discoordination disappeared almost immediately following
Anaesthesiology Intensive Therapy 2016, vol. 48, no 1, 62-64 ISSN 0209-1712 10.5603/AIT.2016.0011 www.ait.viamedica.pl

the initiation of NIV, calling for an iterative re-assessment of preconceived strategy.

2. This case was not acute respiratory distress syndrome (ARDS), but acute hypoxemic non-hypercapnic respiratory failure: the opacities required by the Berlin definition could not be seen on the chest $x$-ray taken minutes after admission to the ED.

3. Although the patient was conscious, cooperative and drowsy (Glasgow 14), he was fully able to answer questions, and denied repeatedly having inhaled heroin. Esquinas [2] reported intubation with Glasgow $\leq 11$. Thus, unconsciousness is irrelevant.

4. The arrhythmia was not sinus tachycardia, but supraventricular arrhythmia: no $\mathrm{P}$ waves were observed on the oscilloscope using a high-speed display. Nevertheless, arrhythmia was, presumably, a consequence of hypoxia, a trivial issue not further discussed in the report [3]. Magnesium followed by amiodarone was aimed at isolating, as early as possible upon presentation, a «pure» ventilatory distress vs. a combined ventilatory and 
circulatory distress. Lung toxicity of a single dose of $450 \mathrm{mg}$ of amiodarone awaits documentation.

5. The interface was a standard oro-nasal mask.

6. High PEEP (up to $20 \mathrm{~cm} \mathrm{H}_{2} \mathrm{O}$ ) generated neither leak nor clinical gastric overdistension, in this patient. I recently handled acute hypoxia $\left(\mathrm{SaO}_{2}=39 \%\right)$ due to postoperative atelectasis, with PEEP increased over $2 \mathrm{~h}$ from 5 to $24 \mathrm{~cm} \mathrm{H}_{2} \mathrm{O}$ (Drager Evita 4XL, low pressure support: PS to Pplat $<30 \mathrm{~cm} \mathrm{H}_{2} \mathrm{O}, \mathrm{FiO}_{2}=1$ ), allowing the pneumologist to perform a bronchoscopy under spontaneous ventilation $\left(\mathrm{SaO}_{2}=100 \%\right.$ when beginning bronchoscopy), without leaks or gastric distension. The reader will decide whether this is again deliberate malpractice or careful, minute by minute, observation.

7. A high tidal volume (Vt) under PS is no trivial issue [4]. At variance with high PS in the setting of chronic obstructive pulmonary disease (COPD) [5], minimal PS $(\leq 8 \mathrm{~cm})$ to compensate for the valves and tubing [6] will generate a low Vt: following the setting up of a high PEEP the lung operates on the highest slope of the pressure-volume curve [7]. The observed Vt was 250-500 mL (not 800-1200 mL as stated by Skoczynski), compatible with permissive hypercapnia (46-69 mm $\mathrm{Hg}$ ) in a quiet patient with respiratory drive depressed by heroin. This technique was delineated earlier [8]. Guldner proposed similar analysis in animals [9]: see note added in proof [3].

8. Skoczynski and Esquinas question the use of excessively high $\mathrm{FiO}_{2}\left(\mathrm{FiO}_{2}=1\right)$. However, the definition of excessive use of $\mathrm{O}_{2}$ is an $\mathrm{FiO}_{2}>0.5$ when $\mathrm{SaO}_{2}$ is $>92 \%$, for up to $12-30 \mathrm{~h}$, and excluding the "first $6 \mathrm{~h}$ of shock" [10]. Given a $P / F \approx 57$, in the $E D$, the patient received $\mathrm{FiO}_{2}=1$, en route toward intubation and controlled mechanical ventilation. $\mathrm{As}_{\mathrm{SaO}}$, remained $<90 \%$ for at least $\approx 5 \mathrm{~h}$, this does not fit with excessively high $\mathrm{FiO}_{2}$. Subsequently, $\mathrm{FiO}_{2}$ was reduced to 0.4 within $\approx 10 \mathrm{~h}$. As severe hypoxia $\left(\mathrm{PaO}_{2}=19-36 \mathrm{~mm} \mathrm{Hg}\right)$ is compatible with life in elite climbers [11], the question may be posed whether benign neglect should be extended to an unstable patient presenting with acute cardio-ventilatory distress $\left(\mathrm{P} / \mathrm{F} \approx 57\right.$ on zero $\mathrm{PEEP}, 30 \mathrm{~L} \mathrm{~min}^{-1}$ on high $\mathrm{O}_{2}$ concentration mask; $\mathrm{P} / \mathrm{F}=75$ on PEEP $=15$ after $2 \mathrm{~h}$ on NIV). Moreover, should $\mathrm{SaO}_{2}=88-92 \%$ be aimed at in the present patient, as proposed in a fully stabilized patient [12]?

The modified NIH table [13] (tab. 1) uses high PEEP-low $\mathrm{FiO}_{2}$ in stabilized intubated mechanically ventilated patients $\left(\mathrm{SaO}_{2} \approx 88-95 \%\right)$, at variance with the questionable combination of high $\mathrm{FiO}_{2}$-low PEEP $[10,12]$ :

Accordingly, in a non-intubated unstabilized patient, PEEP was increased up to $20 \mathrm{~cm} \mathrm{H}_{2} \mathrm{O}$ over $4 \mathrm{~h}$, while $\mathrm{FiO}_{2}$ was lowered to 0.4 over $8 \mathrm{~h}$, after stabilization : "the practice of using higher $\mathrm{FiO}_{2}$ cannot be considered unreasonable under these settings" [10].

The effect of $\mathrm{O}_{2}$ on the respiratory rate (RR) as a function of $\mathrm{PaO}_{2}$ under spontaneous ventilation-PS [14] in the setting of $A R D S$, is to be taken into account to lower the work of breathing, at variance with COPD. Therefore, setting a $88-92 \%$ goal in the setting of invasive controlled mechanical ventilation in ARDS in stabilized intubated patients [12] does not apply to the early use of high PEEP-spontaneous ventilation in an unstabilized patient under NIV.

As to the question whether high $\mathrm{FiO}_{2}$ acts synergistically with other insults to worsen alveolar damage, a "safe level and duration of $\mathrm{O}_{2}$ exposure has not been established even in normal humans"[12]. Accordingly, a cut-off point of $\mathrm{FiO}_{2} \leq 0.6$ for $8 \mathrm{~h} 45$ could not be retrieved from the reference [12] provided by Skoczynski and Esquinas. Avoiding the closingopening of alveoli (atelectrauma) with high PEEP presumably avoided inflammation and terminated swiftly the disease. Any synergistic effect of high $\mathrm{FiO}_{2}$ and inflammation appears irrelevant, given the short time course of the disease.

Can 9 to $10 \mathrm{~h}$ be considered a swift recovery? To my surprise, the intensivist in charge on day 2 terminated the NIV at $08 \mathrm{~h} 30 \mathrm{am}$. In the setting of ARDS, P/F increases over $72 \mathrm{~h}$ or more $[15,16]$. Thus, the reader may decide whether a recovery time over $10 \mathrm{~h}$ is swift or not (day 1, $10 \mathrm{pm}$ : $\mathrm{P} / \mathrm{F} \approx 57$ on zero-PEEP, high $\mathrm{O}_{2}$ concentration mask; day 2,08 $45 \mathrm{am}: \mathrm{P} / \mathrm{F}=240, \mathrm{PEEP}=15, \mathrm{FiO}_{2}=0.4$ ).

Secondly, how far should NIV go without being detrimental? Let's consider Esquinas' data: a) «in the NIV group, P/F and RR became significantly higher and lower 3-4 hours after randomization» (Fig. 3 in [2]). b) the avoidance of intubation is reported in $54 \%$ of the patients with a $P / F=116 \pm 38$ [17]: given the standard deviation, some of his patients had a low $\mathrm{P} / \mathrm{F} \approx 40-60$, as in our report [3]. Indeed, Pichot [3] observed the phenomenon described by Esquinas $[2,17]$. Nevertheless, the use of NIV in acute respiratory failure demands caution [18]. Firstly, in the setting of severe ARDS ( $P / F=126)$, $84 \%$ of the patients needed intubation [19]. Does this imply that the remaining $16 \%$ should be intubated upfront or should they simply observed even more closely to proceed to intubation if appropriate? Secondly, following extubation after respiratory failure, NIV is associated with a $10 \mathrm{~h}$ delay re: re-intubation and a higher mortality (NIV: 38\%; standard treatment + reintubation: 22\%) [20]. Thus, NIV should not be used (except perhaps in COPD or immuno-compromised patients, or as a bridge to intubation). A sober interpretation only implies that patients presenting a second exacerbation of acute respiratory failure after extubation should be very closely re-assessed, e.g. at least hourly, and their trachea intubated early, as needed, should NIV fail. Individualized minute-by-minute observation in one considered patient (3) does not necessarily agree with epidemiologic findings [20]. 
Altogether, NIV is detrimental when extended too far. Indeed, one referee complimented our non-invasive management: "avoid tracheal tubes, minimize sedation, prevent ventilator-induced lung injury and nosocomial infections" [21]. Conversely, another referee considered this [3] management as malpractice $(P 140,17)$. Again, the reader will decide whether our concluding insistence on minute by minute re-assessment in a highly restricted subset [3] was conservative enough.

\section{ACKNOWLEDGEMENTS}

Conflict of interest: Luc Quintin holds a US patent 8703 697, April 22 2014: Method for treating early severe diffuse acute respiratory distress syndrome.

\section{References:}

1. Baillard C, Fosse JP, Sebbane Met al.: Noninvasive ventilation improves preoxygenation before intubation of hypoxic patients. Am J Respir Crit Care Med 2006; 174: 171-177.

2. Ferrer $M$, Esquinas A, Leon M, Gonzalez $G$, Alarcon A, Torres A: Noninvasive ventilation in severe hypoxemic respiratory failure: a randomized clinical trial. Am J Respir Crit Care Med 2003; 168: 1438-1444.

3. Pichot $C$, Petitjeans F, Ghignone M, Quintin L: Swift recovery of severe acute hypoxemic respiratory failure under non-invasive ventilation. Anaesthesiol Intensive Ther 2015; 47: 138-142. doi: 10.5603/AIT.a2014.0053.

4. Freebairn $R$, Hickling KG: Spontaneous breathing during mechanical ventilation in ARDS. Crit Care Shock 2005; 8: 61-66.

5. Brochard L, Harf A, Lorino $H$, Lemaire F: Inspiratory pressure support prevents diaphragmatic fatigue during weaning from mechanical ventilation. Am Rev Respir Dis 1989; 139: 513-521.

6. L'Her E, Deye N, Lellouche F et al.: Physiologic effects of noninvasive ventilation during acute lung injury. Am J Respir Crit Care Med 2005; 172: 1112-1128.

7. Katz JA, Marks JD: Inspiratory work with and without continuous positive airway pressure in patients with acute respiratory failure. Anesthesiology 1985; 63: 598-607.

8. Galland C, Ferrand FX, Cividjian A et al.: Swift recovery of severe hypoxemic pneumonia upon morbid obesity. Acta Anaesthesiol Belg 2014; 65: 109-117.

9. Guldner A, Pelosi P, Gama de Abreu M: Spontaneous breathing in mild and moderate versus severe acute respiratory distress syndrome. Curr Opin Crit Care 2014; 20: 69-76.
10. Rachmale S, Li G, Wilson G, Malinchoc M, Gajic O: Practice of excessive $\mathrm{F}(\mathrm{IO}(2))$ and effect on pulmonary outcomes in mechanically ventilated patients with acute lung injury. Respir Care 2012; 57: 1887-1893.

11. Grocott MP, Martin DS, Levett DZ et al.: Arterial blood gases and oxygen content in climbers on Mount Everest. N Engl J Med 2009; 360: 140-149. doi: 10.1056/NEJMoa0801581.

12. Aggarwal NR, Brower RG: Targeting normoxemia in acute respiratory distress syndrome may cause worse short-term outcomes because of oxygen toxicity. An Am Thorac Soc 2014; 11: 1449-1453. doi: 10.1513/AnnalsATS.201407-297PS.

13. Brower RG, Lanken PN, Maclntyre $N$ et al.: Higher versus lower positive end-expiratory pressures in patients with the acute respiratory distress syndrome. N Engl J Med 2004; 351: 327-336.

14. Pesenti A, Rossi N, Calori A, Foti G, Rossi GP: Effects of short-term oxygenation changes on acute lung injury patients undergoing pressure support ventilation. Chest 1993; 103: 1185-1189.

15. Villar J, Perez-Mendez L, Lopez J et al.: An early PEEP/FIO trial identifies different degrees of lung injury in patients with acute respiratory distress syndrome. Am J Respir Crit Care Med 2007; 176: 795-804.

16. Talmor D, Sarge T, Malhotra A et al.: Mechanical ventilation guided by esophageal pressure in acute lung injury. $\mathrm{N}$ Engl J Med 2008; 359: 2095-2104. doi: 10.1056/NEJMoa0708638.

17. Antonelli $M$, Conti G, Esquinas A et al.: A multiple-center survey on the use in clinical practice of noninvasive ventilation as a first-line intervention for acute respiratory distress syndrome. Crit Care Med 2007; 35: 18-25.

18. Esteban A, Anzueto A, Frutos F et al. Characteristics and outcomes in adult patients receiving mechanical ventilation: a 28-day international study. JAMA 2002; 287: 345-355.

19. Thille AW, Contou D, Fragnoli C, Cordoba-Izquierdo A, Boissier F, Brun-Buisson C: Non-invasive ventilation for acute hypoxemic respiratory failure: intubation rate and risk factors. Crit Care 2013; 17: R269.

20. Esteban A, Frutos-Vivar F, Ferguson ND et al: Noninvasive positive-pressure ventilation for respiratory failure after extubation. N Engl J Med 2004; 350: 2452-2460.

21. Terragni PP, Birocco A, Faggiano C, Ranieri VM: Extracorporeal $\mathrm{CO}_{2}$ removal. Contrib Nephrol 2010; 165: 185-196. $10.1159 / 000313758$

\section{Corresponding author:}

Luc Quintin MD, PhD

Physiologie

Campus de la Doua

8 Rue R Dubois

69622 Villeurbanne, France

e-mail: lucquintin@yahoo.com

Anaesthesiology Intensive Therapy 2016, vol. 48, no 1, 64-66 ISSN 0209-1712 10.5603/AIT.2016.0012 www.ait.viamedica.pl

\section{The role of Argentine Federation of Associations of Anaesthesia, Analgesia and Reanimation}

\author{
Wojciech Stanisław Pietrzyk
}

St. Alexander Hospital in Kielce

Due to previous friendly relationships with Argentinean anesthesiologists, especially with Pedro Klinger, MD, PhD, with whom I worked in the past in Ibiza, Spain, as well as an invitation to participate in the $15^{\text {th }}$ World Congress of Anaesthesiologists (WCA), I had an opportunity to familiarize myself with the organization of anaesthesiology care in Argentina. Moreover, this year I was pleased to visit this wonderful country and be hosted by my Argentinean friends, including Marisa Bard, MD, a specialist in anaesthesiology with Polish roots. Argentina is acountry of emigrants and has accepted in past a lot of Polish people, several of whose descendants have become outstanding figures in the medical world. 
Although the territory of Argentina is many times bigger than that of Poland, both countries are joined by multiple similarities, such as size of population. As in Poland, many Argentinean specialists in anaesthesiology work abroad, either permanently or temporarily.

In Argentina alone there are approximately 3800 specialists in anesthesiology, about 3750 of whom are members of Federación Argentina de Asociaciones de Anestesia, Analgesia y Reanimación (FAAAAR), a figure based on personal contact data from 2012. In contrast, based on the Statistical Yearbook for 2012, the number of specialists in anaesthesiology and intensive care in Poland is 3414, placing it in 5th position among other specializations. Taking into consideration the significant financial outlay of the Ministry of Health on anaesthesiology residencies, it may be admitted that the number of specialists in anaesthesiology in Poland will significantly increase in the near future.

In Argentina, where specialized training in anaesthesiology is conducted by FAAAAR, the number of specialists is adjusted to the needs of the healthcare service market. This was even the cause of a minor scandal during the opening ceremony of the $15^{\text {th }}$ WCA in Buenos Aires. A group, whose political position was difficult to assess, organized a protest in front of the entrance to the congress center against the "monopoly" of FAAAAR in the shaping of a so-called "mafia" position of anaesthesiology within the structure of the Argentinean healthcare system. This was accompanied by the "flooding" of congress participants going for opening ceremony by scattering machines with thousands of leaflets, informing them about the huge income of anaesthesiologists and their Federación. Additionally, the soundtrack from “The Godfather" movie by Coppola was heard being played over large speakers. Undoubtedly, these professionally organized demonstrators achieved their goal as many anaesthesiologists, including myself, were intrigued to explore the topic further.

The history of clinical anesthesiology in Argentina is much longer than that of Poland. Indeed, the first Association of Argentinean Anaesthesiologists was founded in 1936, and since 1948 they have been trained through specialized courses and, moreover, have issued their own scientific journal. This was for certainly connected with the country's economic prosperity, placing Argentina in $8^{\text {th }}$ position among all economies worldwide. Unfortunately, subsequent social and political turmoil, the unstable nature of the Peron government, the bloody rule of the military junta, as well as serious economic crises have all slowed the development of this beautiful country.

Social conversations show, that the average Argentinean anaesthesiologist, working only in a public hospital in Buenos Aires earns the equivalent of approximately 2,500 euro on average. However, physicians working in private hospitals (the majority) earn as much as 5,000 euro. Obviously, there is remuneration for a so-called job position (a specific number of working hours), without any duties. There are also some differences regarding working discipline. Basically, the wages of anaesthesiologists depend on the quantity and type of performed anaesthesia. Each and every type has its own calculated price.

Who is responsible for the determination of the stakes? Indeed, this question draws us to FAAAAR which, at a national level, unifies 30 regional anaesthesiology associations. One of them is Asociacion Santa Crucena de Anesthesia, Analgesia y Reanimacion in Rio Gallegos in Patagonia, which is the capital of Santa Cruz province.

Generally, each of the Argentinean provinces has its own regional association of anaesthesiologists. Here, the most important and most numerous are those involving the conurbation of Buenos Aires with many millions inhabitants, due to its large population and number of hospitals. Although, apart from during the residency period, membership of the association is not obligatory, the vast majority of anaesthesiologists are permanent members of it. Why? Indeed, when a specialist of anaesthesiology seeks a position, mainly in private hospital, there is the question of determining his or her salary. This falls within the remit of the regional FAAAAR association, which helps in the negotiations of contracts for each of its members. Although some agreements with insurance companies and their counterparts in the Ministry of Health are also reached, this is conducted at the central level beforehand.

Obviously, this gives FAAAAR an exceptional bargaining position and the possibility to gain high rates of pay for its members. However, if anaesthesiologists work in the private sector, they pay $5 \%$ of their earnings to a FAAAAR account, or $3.5 \%$ if they work in public hospitals and only earn extra money in private hospitals (personal contact information). Is this a lot? Yes, but, personally, I would be happy to pay such an "imposition" in the knowledge that I would gain as good a contract as possible, without having to conduct sometimes very difficult negotiations.

Is there any additional value for an anaesthesiologist being a member of such an association apart from the high rates of pay? Indeed, he or she receives basic insurance and the complimentary advice of the best legal offices in Buenos Aires in cases of conflict with employers or civil actions concerning damages. Additionally, fellowships, lasting several months, have been founded for young, talented anaesthesiologists (mainly in the US, where several dozen go annually), who then return to Argentina introducing new treatment methods. Each anaesthesiologist, as a member of the association, acquires the entitlement to significant financial relief for many months in unforeseen emergencies which make one's previous standard of living impossible to sustain. There are also many and various benefits connected with FAAAAR membership which were not disclosed to me as a foreigner. Each member has also the possibility to save money in pension founds, co-managed and controlled by the federation. In light of the current prognosis regarding our own pensions in Poland, this last aspect is of special interest. 
Obviously, despite socio-economic issues and the educational process for specialists in anaesthesiology, FAAAAR conducts a wide range of scientific activities, including basic research and clinical trials, establishes current effective standards of anaesthesia safety and supports anaesthesiology associations from poorer countries of South America.

FAAAAR is a wealthy organization, having its headquarters in a beautiful office in the center of Buenos Aires, owning a museum of anaesthesiology history and, moreover, is one which can afford to organize the World Congress of Anaesthesiologists. To achieve the aims of its statute, the association employs the best lawyers and managers. However, the decisive vote in crucial questions is given to anaesthesiologists themselves, as they maintain their organization. The statutes of regional associations, as well as FAAAAR, have a democratic character, allowing ordinary members to really have an influence on the organization's activities. The "senators" are elected for tenure, and have the right to vote. Young people with "managerial" approach are preferred. Surrounded by universally respected professors who are sitting on particular commitees and can concentrate on scientific and educational questions and set appropriate standards.

Nevertheless, in some private conversations some delicate objections arose regarding the power and omnipotence of FAAAAR. This is somehow a contemporary, super-modern version of "anesthesiologists' guilt", protecting its members' affairs, but also demanding, not only in area of continuous medical education. Well, something for something...

There were no detailed answers to these particular questions. I am also aware, that despite friendly relations enhanced by the delicious Malbek in Mendoza or Tierra del Fuego, many affairs are either internal or confidential for FAAAAR members and my knowledge is only superficial and limited.

As for Poland, we all know the situation is certainly the opposite to Argentina. There are a few decisive centers regarding anaesthesiology and intensive care, and each of them has rather distinctive statute aims. However, from time to time PTAilT, the trade union of anaesthesiologists and National Consultant join forces. The last time this concerned intensive care specialization although its effects remain to be seen.

Perhaps it is worth considering and discussing some possible solutions which are effective in other countries, such as Argentina, a country which for many years has protected the material status of anaesthesiologists while under conditions of permanent financial crisis. However, our politicians' mouths are full of "medical socialism" featuring declarations (based on populism) and slogans regarding patients claims (attitude of entitlement), while on the Polish healthcare service market "broad capitalism" rules.

\section{ACKNOWLEDGEMENTS}

1. The author declares no financial disclosure.

2. The authors declares no conflict of interest.

\section{Corresponding author:}

Wojciech Pietrzyk MD, PhD

St. Alexander's Hospital in Kielce

ul. Kościuszki 25, 25-316 Kielce, Poland

e-mail:dr.pietrzyk.w@gmail.com

\section{Snaring swans: intraoperative knotting of pulmonary artery catheters}

\author{
Lukasz Starzyk ${ }^{1}$, Eric Yao ${ }^{2}$, Graham Roche-Nagel ${ }^{3}$, \\ Marcin Wasowicz ${ }^{2}$ \\ ${ }^{1}$ Department of Anaesthesia and Pain Medicine, University Hospital \\ Bern, Bern, Switzerland \\ ${ }^{2}$ Department of Anaesthesia and Pain Management, Toronto General \\ Hospital, University Health Network, Toronto, Canada \\ ${ }^{3}$ Division of Vascular Surgery, Toronto General Hospital, University \\ Health Network, Toronto, Canada
}

Key words: knot, Swan-Ganz catheter, percutaneous removal

First introduced in 1970 by HJ Swan and W Ganz, the pulmonary artery catheter (PAC) is an important invasive diagnostic and hemodynamic monitoring tool widely used for patients in cardiac and transplant anaesthesia, or for unstable patients in the intensive care unit. Rare acute complications such as catheter knotting, arterial perforation, thrombosis and arrhythmias are well-documented, with the lattermost being the most prevalent of complications [1]. This letter focuses on PAC knotting, which has an estimated incidence of $0.03 \%$ of all PAC insertions [2]. We present a case involving a knotted and entrapped PAC during open heart surgery and describe the management of this complication. This report also reviews the current methodology for the removal of a knotted PAC, both invasive and non-invasive.

A 32 year-old male (who consented to the writing of this report) was admitted to our centre with a newly diagnosed congenital partial atrioventricular septal defect (AVSD) and no known other history of previous cardiovascular disease. The patient developed late symptoms of congenital heart 
disease in the form of syncope episodes. On a preoperative transthoracic echocardiogram (TTE), he was found to have a primum atrial septal defect combined with moderate to severe left $A V$ valve regurgitation and moderate right $A V$ valve regurgitation. Right ventricular enlargement with preserved systolic function, as well as normal left ventricular function were noted. The patient's only comorbidity included mild gastroesophageal reflux disease treated with proton pump inhibitors.

The patient underwent a partial AVSD repair with primum atrial septal defect closure using autologous pericardium, cleft closure of the left $\mathrm{AV}$ valve and two partial left $\mathrm{AV}$ valve commissurotomies.

Intraoperatively, standard monitors were applied, including a five-lead ECG, non-invasive blood pressure and pulse oximeter. An arterial line and a 16G IV line were inserted. The patient was then preoxygenated and induced with midazolam, fentanyl, propofol and rocuronium bromide. Anaesthesia was maintained with sevoflurane, with ranging intraoperative minimum alveolar concentration (MAC) levels between 0.7 and 1.0. Entropy, in combination with the patient's clinical appearance, was used as a guide for sleep depth. After the placement of a Cordis introduction sheath (8.5 Fr., Arrow International, Reading, $\mathrm{PA}$, USA) into the right internal jugular vein, a pulmonary artery catheter (7 Fr. $110 \mathrm{~cm}$, Edwards Lifescience, Irvine (A, USA) was inserted through the sheath. The balloon was inflated with the standard $1.5 \mathrm{cc}$ of air and the catheter was introduced to a depth of approximately $50 \mathrm{~cm}$. At this point, the pressure curve of the pulmonary artery was identified. The balloon was subsequently deflated and the catheter kept in position for hemodynamic measurements. During the repair of the congenital cardiac lesion, the catheter was withdrawn into the superior vena cava (SVC) until central venous pressure tracing was confirmed on the distal port of the catheter.

The cardiopulmonary bypass (CBP) course was uneventful, while CPB and total cross clamp time were 67 and 45 minutes, respectively. To obtain hemodynamic measurements after successful weaning from the bypass, the anaesthesia team attempted refloating the catheter.

After 4-5 attempts with maximal advancement of the catheter to a maximum depth of $45-50 \mathrm{~cm}$, the PAC sleeve became contaminated with blood (valve failure) and it was decided to discontinue monitoring through the PAC. At this point, the operation was completed with a hemodynamically stable patient and without any other intraoperative complications.

Upon attempts to remove the catheter postoperatively before leaving the operating room, it became lodged at 16-18 cm (Fig. 1). As the catheter could be advanced into the RV again, the assumption was made that it had not

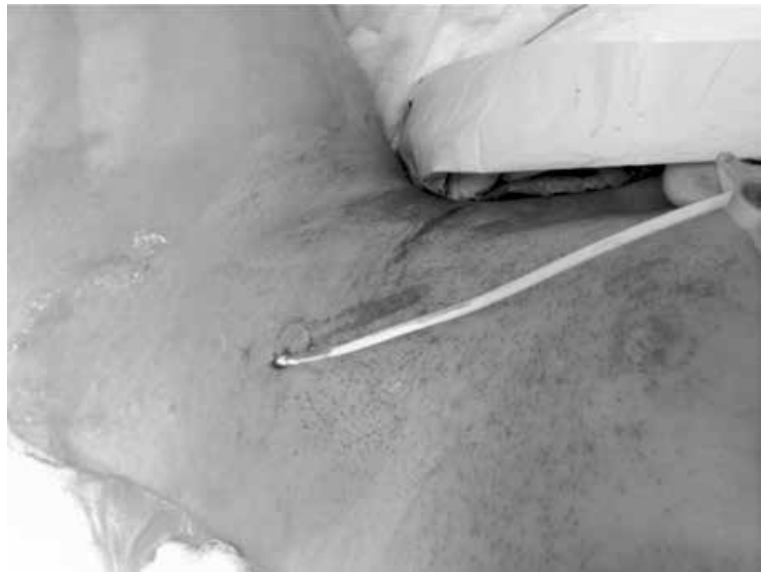

Figure 1. Patient's head on the right side: Cordis sheath at this stage removed, knotted PAC stuck at $10 \mathrm{~cm}$ at skin level

been tied or sutured to any of the surgical repair sites. To confirm this thesis, a TEE exam was performed which could not identify the PAC in the cardiac chambers or adherent to the SVC. To have further visual confirmation of the position and the actual problem, a chest x-ray (CXR) (Fig. 2) was performed, showing the position of the catheter in the SVC/ /internal jugular vein (IJV) with obvious knotting. In this situation, a vascular surgeon was consulted. As the diameter of the knot on the CXR was not much bigger than the original PAC diameter, the decision was made to try and remove the catheter without any surgical intervention. With firm and continuous pulling force and counter traction on the initial puncture site, the catheter was slowly removed (Fig. 2). A knot was indeed found at the distal portion of the extracted catheter about $8 \mathrm{~cm}$ from the end (Fig. 3, 4).

The further postoperative course remained uneventful and the patient was discharged on the $5^{\text {th }}$ postoperative day.

Knotting of pulmonary artery catheters (PACs) occurs when catheters are repetitively advanced and/or when they are inserted at an excessive length [13]. Warming of the PAC by the blood causes the line to soften, further predisposing it to curl inside heart chambers. The pulmonary artery is typically reached with an insertion of $40-45 \mathrm{~cm}$ and the wedge position at $45-55 \mathrm{~cm}$. Thus, if the pulmonary artery waveform is not observed at $50 \mathrm{~cm}, \mathrm{PAC}$ looping is highly suspect [strongly suspected?? - Please Check] [3]. In cases of suspected knotting of a catheter, it is important use any form of imaging (Fluoroscopy, CXR and/or TEE). Moreover, it is essential to visualize the PAC in order to identify the position, distance and form of the knot before any action is taken. In cases of a loose knot, a guide wire may be introduced through the lumen of the PAC in order to untie the knot before it tightens [4]. 


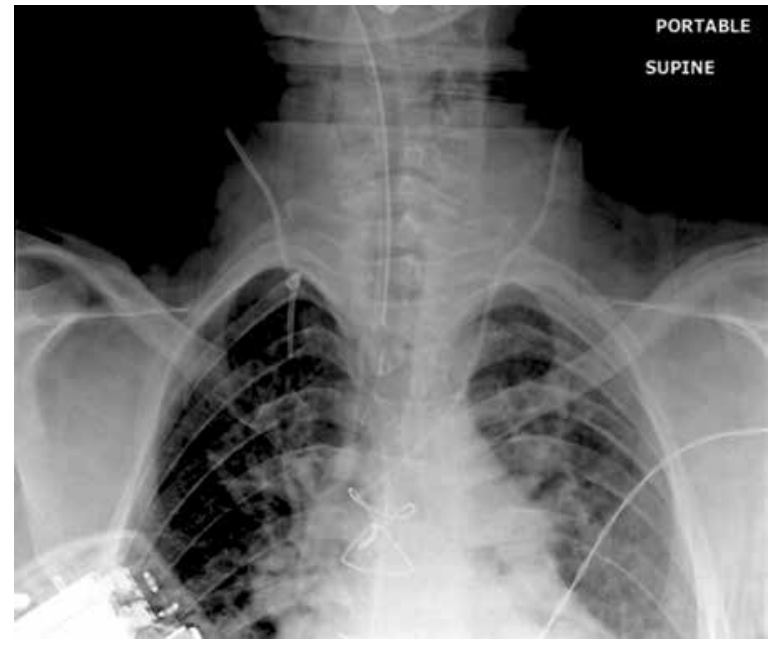

Figure 2. Chest X-Ray with the knotted PAC in situ

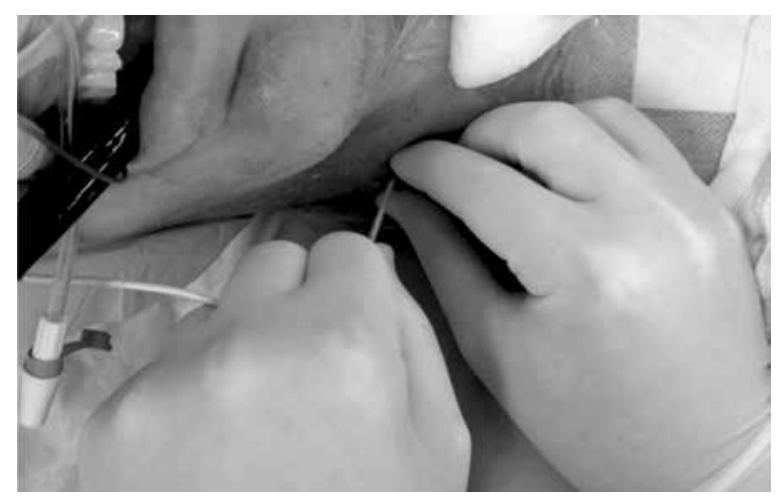

Figure 3. Extraction technique with force and counter force

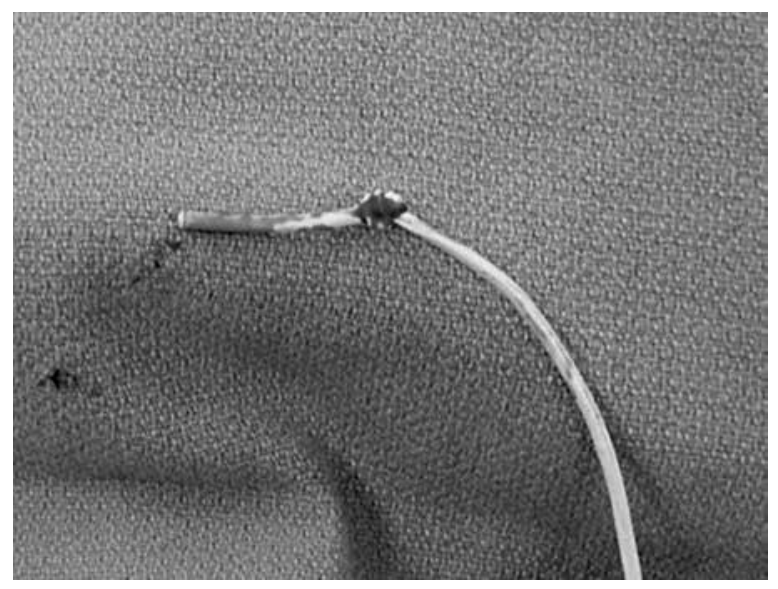

Figure 4. PAC after extraction

In this case, the knot was likely formed during re-advancement of the catheter after it was retracted to clear the surgical field. It is hypothesized that the warm and pliable catheter looped around itself to form a knot while inside the right ventricle. Subsequent traction on the catheter from attempts at removal tightened the knot. Fortunately, the PAC knot diameter was small enough that, with steady traction on the proximal portion of the PAC and counter pressure on the site of PAC insertion on the right IJV, the knot was extracted without complications. Fluoroscopy and further surgical intervention were not required. Therefore, we concluded, that in upper SVC/IJV PAC entrapment, the catheter could be removed with a minimally invasive approach.

Coiling and knotting are rare but serious complications of pulmonary artery catheter insertions. Despite reported incidences of PAC knotting ranging from only $0.2 \%$ to $2.5 \%$ [5], PAC knotting accounts for more than two thirds of all incidences of intravascular catheter looping [6]. Pulmonary artery catheters are susceptible to intravascular knotting in both the intravascular space and around internal cardiac structures, with the most common sites being the right atrium, the right ventricle and the superior vena cava [5]. Procedural factors contributing to PAC coiling include blind introduction of the catheter, small diameter and inflexibility of the catheter, incomplete balloon inflation during introduction and multiple flotation attempts. Predisposing patient risk factors include dilated right heart chambers, tricuspid valve regurgitation, mechanical valves and abnormal venous anatomy [7]. Though the occurrence of PAC knotting is rare, interventions employed in the extraction of the knot, both surgical and non-surgical, frequently introduce a significant risk of additional complications and increase patients' mortality and morbidity [3]. Problems associated with knotted PACs include infection (if left in situ), vessel or chamber rupture, thrombosis and arrhythmia. Table 1 summarizes the various types of interventions that have been employed to retrieve an intravascular knotted PAC. Major surgical intervention (sternotomy) poses the obvious risks of prolonged intubation, increased blood loss and increased cardiopulmonary bypass pump run time. As such, surgery is recommended only for complex PAC knots, such as large or multiple looped knots [5]. A less invasive surgical procedure for PAC knot removal is a venous cut-down, used in combination with a large bore introducer sheath or a dilator fitted over the top of the PAC. The sheath is used to reduce the knot size with traction, and as a guide for the knot during the course of its removal through the venous incision. Issues associated with this approach include the potential introduction of an air embolus or excessive bleeding via the venous incision [11]. Therefore, venous cut-down is recommended only for knots that are either too tight or too proximal [16]. Small, tightened knots can also be extracted via simple traction (as was done in this case) through the original insertion site. One concern with this method is that it introduces the risk for venous laceration, or catheter rupture causing a foreign body embolus $[16,18]$. Further- 
Table 1. Summary of various interventions used to extract knotted pulmonary artery catheters

\begin{tabular}{|c|c|c|c|}
\hline Reference & Presenting illness/procedure & Site of insertion & Method of PAC knot extraction \\
\hline [8] & $\begin{array}{l}\text { Bronchial carcinoma and } \\
\text { concomitant chronic bronchitis } \\
\text { and obstructive emphysema }\end{array}$ & Right basilic vein & Skin incision enlarged and PAC removed \\
\hline [9] & $\begin{array}{l}\text { Fracture dislocation of cervical } \\
\text { spine with respiratory and renal } \\
\text { failure }\end{array}$ & Right subclavian vein & $\begin{array}{l}\text { Billiary stent catheter introduced over PAC and knot was removed } \\
\text { together with the catheter sheath through the venipuncture site }\end{array}$ \\
\hline$[10]$ & $\begin{array}{l}\text { Elective coronary } \\
\text { revascularization }\end{array}$ & Right internal jugular vein & $\begin{array}{l}\text { Knot was tighted against introducer and extracted together } \\
\text { through skin incision, under fluoroscopic guidance }\end{array}$ \\
\hline$[11]$ & $\begin{array}{l}\text { Abdominal aortic aneurysm } \\
\text { dissection and repair }\end{array}$ & Right internal jugular vein & Transfemoral removal of knot under fluoroscopic guidance \\
\hline$[12]$ & $\begin{array}{l}\text { Rheumatic heart disease with } \\
\text { mitral stenosis and emergency } \\
\text { MV replacement }\end{array}$ & Right internal jugular vein & $\begin{array}{l}\text { Guide wire through PAC lumen with transfemoral biopsy forceps } \\
\text { manipulation to untie knot. Extracted percutaneously. }\end{array}$ \\
\hline [13] & $\begin{array}{l}\text { CT-guided percutaneous } \\
\text { drainage of splenic abscess, } \\
\text { developed septic shock and } \\
\text { respiratory failure }\end{array}$ & Right subclavian vein & $\begin{array}{l}\text { Tracheostomy dilator inserted over catheter and PAC was } \\
\text { removed along with the dilator }\end{array}$ \\
\hline$[14]$ & CABG & Right internal jugular vein & Re-sternotomy after traction attempts caused PA rupture \\
\hline [6] & $\begin{array}{l}\text { MV replacement and tricuspid } \\
\text { annuloplasty }\end{array}$ & Left subclavian vein & Re-sternotomy; removed through SVC purse string incision \\
\hline$[15]$ & Cardiac surgery & Right internal jugular vein & Untied intraoperatively by surgeons \\
\hline$[16]$ & Total gastrectomy & Right internal jugular vein & $\begin{array}{l}\text { Knot was attached to basket catheter and removed from the } \\
\text { saphenous vein through an inguinal incision under fluoroscopic } \\
\text { guidance }\end{array}$ \\
\hline [17] & $\begin{array}{l}\text { Liver resection for cirrhosis and } \\
\text { liver cancer }\end{array}$ & Right internal jugular vein & $\begin{array}{l}\text { Kinked introducer sheath and looped PAC extracted together } \\
\text { percutaneously under fluoroscopy }\end{array}$ \\
\hline [18] & $\begin{array}{l}\text { Minimally invasive MV } \\
\text { reconstruction for } \mathrm{MV} \\
\text { regurgitation }\end{array}$ & Right internal jugular vein & $\begin{array}{l}\text { Knot was tightened against introducer sheath and extracted } \\
\text { percutaneously }\end{array}$ \\
\hline [4] & $\begin{array}{l}\text { Worsening heart failure } \\
\text { symptoms }\end{array}$ & Right internal jugular vein & Small skin cut-down and PAC removal under fluoroscopy \\
\hline$[19]$ & $\begin{array}{l}\text { End-stage heart failure with } \\
\text { respiratory insufficiency }\end{array}$ & Right subclavian vein & Transfemoral removal under fluoroscopic guidance \\
\hline$[20]$ & Cardiac arrest & Right internal jugular vein & $\begin{array}{l}\text { Tightening of knot unravelled via femoral approach with the aid } \\
\text { of a J-wire under fluoroscopy guidance }\end{array}$ \\
\hline
\end{tabular}

more, forced removal of a PAC knotted around an internal cardiac structure could potentially result in tricuspid valve and papillary muscle avulsion or chordae tendinae embolism. The literature suggests interventional radiological techniques as the preferred method of PAC knot removal. The knotted PAC can be removed heterotopically via the saphenous or femoral vein under fluoroscopic guidance $[19,20]$. A dotter basket or loop snare catheter may also be employed to snare the knot and pull it out. However, even transfemoral removals of PAC knots pose a risk of venous laceration throughout its longer intravascular exit course [19], as well as concerns about contamination of the blood stream by the non-sterile proximal end of the catheter [16]. The alternative, minimally invasive management of a knotted PAC involves the threading of a core-guided wire through the lumen of the coiled PAC under fluoroscopy in an attempt to straighten the catheter and untie the knot.
This method proves difficult if the knot has become too coiled or tightened [16].

In summary, we conclude that PAC knotting is a complication of PAC monitoring that can potentially lead to dangerous outcomes for the patient. To minimize the risk of PAC knotting, pressure waveforms should be continually monitored and repeated while excessive advancement of the catheter should be avoided. Failure to detect a pulmonary artery waveform at a maximum advancement of $55-60 \mathrm{~cm}$ suggests catheter coiling. Methods for extracting a formed PAC knot warrant further investigation. Based on current knowledge, it is advised to use imaging (CXR, fluoroscopy and or TEE) to assess the quality and complexity of the knot in order to choose the appropriate intervention. Although the traction with counter pressure method is the least invasive, it warrants good accessibility to the initial puncture site while conditions such as intracardiac knot- 
ting may preclude its use. If the knotted catheter can be retracted into a proximal position, it may be safe to remove it with gentle traction without further invasive methods. The potential complications of knot removal must be carefully understood and reviewed prior to proceeding with any intervention.

\section{ACKNOWLEDGEMENTS}

1. The authors declare no financial disclosure.

2. The authors declare no conflict of interest.

\section{References:}

1. American Society of Anesthesiologists Task Force on Pulmonary Artery Catheterization: Practice guidelines for pulmonary artery catheterization: an updated report by the American Society of Anesthesiologists Task Force on Pulmonary Artery Catheterization. Anesthesiology 2003; 99: 988-1014.

2. Evans DC, Doraiswamy AV, Prosciak MP et al.: Complications associated with pulmonary artery catheters: a comprehensive clinical review. Scand J Surg 2009; 98: 199-208.

3. Eshkevari L, Baker B: Occurrence and removal of a knotted pulmonary artery catheter: a case report. AANA J 2007; 75: 423-428.

4. Chen L, Huang P: Entrapment of a Swan-Ganz catheter. J Chin Med Assoc 2007; 70: 213-214.

5. Aggarwal N, Kupfer Y, Yoon T, Tessler S: Pulmonary artery catheter coiled in the main pulmonary artery trunk. BMJ Case Rep 2013. doi: $10.1136 / \mathrm{bcr}-2013-200049$.

6. Georghiou GP: Knotting of a pulmonary artery catheter in the superior vena cava: surgical removal and a word of caution. Heart 2004; 90: e28-e28.

7. Chen C, Chen K, Taso S, Lin S, Lu K: Perforation of the right innominate vein by pulmonary artery catheter introducer sheath: a case report. J Clin Anesth 2009; 21: 206-208. doi: 10.1016/j.jclinane.2008.06.040

8. Daum S, Schapira M: Intracardiac knot formation in a SwanGanz catheter. Anesth Analg 1973; 52: 862-863.

9. Dach JL, Galbut DL, LePage JR:The knotted Swan-Ganz catheter: new solution to a vexing problem. Am J Roentgenol 1981; 137: 1274-1245.

10. Tremblay N, Taillefer J, Hardy JF: Successful non-surgical extraction of a knotted pulmonary artery catheter trapped in the right ventricle. Can J Anaesth 1992; 39: 293-295.
11. Ismail KM, Deckmyn TJ, EV, Vandermeersch E, Stockx L: Nonsurgical extraction of intracardiac double-knotted pulmonary artery catheter. J Clin Anesth 1998; 10: 160-162.

12. Mehta N, Lochab SS, Tempe DK, Trehan V, Nigam M: Successful nonsurgical removal of a knotted and entrapped pulmonary artery catheter. Cathet Cardiovasc Diagn 1998; 43: 87-89.

13. Akkerhuis MJO, Baul CG, Bauland CG, Voets AJ: Percutaneous removal of a knotted pulmonary artery catheter using a tracheostomy dilator. Crit Care (London, England) 1999; 3: 131-133.

14. Huang $G$, Wang $H$, Chen $C, H o S$, Wong C: Pulmonary artery rupture after attempted removal of a pulmonary artery catheter. Anesth Analg 2002; 95: 299-301.

15. Matsuda T, Inoue S, Keiichi S, Furuya H: Images in Anesthesia: accidental knot formation of a pulmonary artery catheter. Can J Anaesth 2004; 51: 1010.

16. Lopes MC, de Cleva R, Zilberstein B, Gama-Rodrigues JJ: Pulmonary artery catheter complications: report on a case of a knot accident and literature review. Rev Hosp Clin Fac Med Sao Paulo 2004; 59: 77-85.

17. Bhatia P, Saied NN, Comunale ME: Management of an unusual complication during placement of a pulmonary artery catheter. Anesth Analg 2004; 99: 669-671.

18. Bossert T, Gummert JF, Bittner HB, Barten M, Walther T, Falk V, MohrFW: Swan-Ganz catheter induced severe complications in cardiac surgery: Right ventricular perforation, knotting, and rupture of a pulmonary artery. J Card Surg 2006; 21: 292-295.

19. Papakostas JC, Papadopoulos LN, Arnaoutoglou HM, KarahaliouA, Matsagas MI: Transfemoral removal of a knotted Swan-Ganz catheter. Can J Surg 2008; 51: E107-108.

20. Rahim SA, Franke R, Mathew V: Removal of a knotted SwanGanz catheter. J Am Coll Cardiol 2009; 53:e91. doi: 10.1016/j. jacc.2009.03.017.

\section{Corresponding author:}

Lukasz Starzyk, MD

Staff Anaesthesiologist

Department of Anaesthesia and Pain Medicine

University Hospital Bern

3010 Bern, Switzerland

e-mail:Lukasz.Starzyk@insel.ch 